\title{
Efficacy of oral fenofibrate in management of unconjugated hyperbilirubinemia in the neonate
}

\author{
Pathak NN $N^{1}$ Deka Anupama', Saikia Bidyut B \\ Received on December 31, 2019; editorial approval on January 10, 2020
}

\begin{abstract}
Introduction: Neonatal jaundice is one of the commonest neonatal problems health care providers encounter every day. Though there are effective treatments like phototherapy and exchange transfusions, there is a need to search for an inexpensive, safe and effective drug therapy for this condition. Objectives were to study the efficacy of oral fenofibrate, a lipidlowering drug in adults, in the management of unconjugated neonatal hyperbilirubinemia. Materials and methods: Study design: Prospective, double-blinded. Setting: NICU of Silchar Medical College, from July 2017 to June 2018. 100 newborns with unconjugated hyperbilirubinemia divided into 2 groupscontrol and intervention, 50 in numbers in each group. Efficacy of oral fenofibrate was determined by comparing the control group (receiving phototherapy alone) to the intervention group (fenofibrate + phototherapy) by measuring serum bilirubin level at 0, 12, 24 and 48 hours and the duration of phototherapy. Results: The mean value of total serum bilirubin (TSB) in the fenofibrate group at 24 and 48 hours of starting phototherapy is considerably lower than the control group $(p<0.005$ and 0.001 respectively). No side effects of fenofibrate observed. Conclusion: Fenofibrate appears to be an effective drug in the management of unconjugated neonatal

hyperbilirubinemia.
\end{abstract}

Keywords: Unconjugated; neonatal hyperbilirubinemia; phototherapy.

\section{INTRODUCTION}

Bilirubin is a pigment derived from the breakdown of heme-containing proteins in the reticuloendothelial systems as shown in Figure 1. The normal adult serum bilirubin level is less than $1 \mathrm{mg} / \mathrm{dl}$. Adults appear to be jaundiced when the serum bilirubin level is greater than $2 \mathrm{mg} / \mathrm{dl}$ and in newborns when it is greater than $7 \mathrm{mg} / \mathrm{dl} .{ }^{1}$

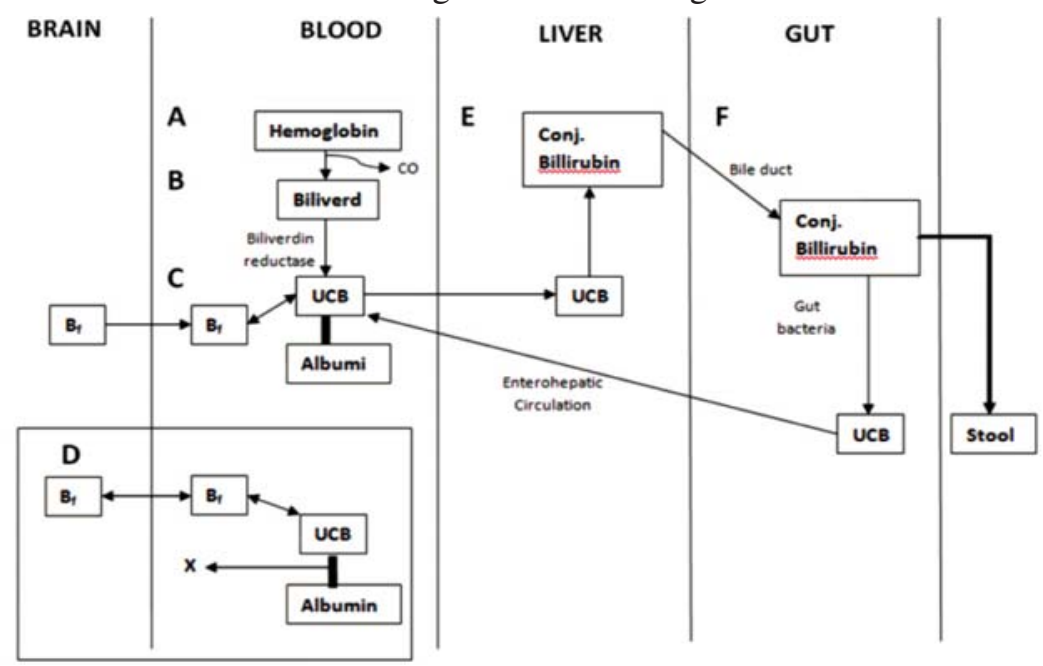

Figure 1 Bilirubin metabolism

\footnotetext{
Address for correspondence:

${ }^{1}$ Associate Professor (Corresponding author)

Mobile: +919435341810

Email: nripenpathak@yahoo.co.in

${ }^{2}$ Professor and Head

${ }^{3}$ Junior Resident

Department of Pediatrics

Silchar Medical College, Assam, India.
} 
Here (A) Hemoglobin is converted to biliverdin, catalyzed by heme oxygenase and producing carbon monoxide in a concentration equimolar with bilirubin; (B) Nontoxic biliverdin is catalyzed by biliverdin reductase to unconjugated bilirubin (UCB), a natural anti-oxidant at low levels, but neurotoxic at high levels; (C) UCB is nonpolar and virtually insoluble in water at neutral $\mathrm{pH}$ and is bound to serum albumin. Thus little UCB exists in the form of unbound or free unconjugated bilirubin; (Bf), but it is $\mathrm{Bf}$ and not albumin-bound UCB that enters the brain; (D) Interstitial fluid, and cerebrospinal fluid, and is responsible for neurotoxicity. UCB is taken up by liver cells; (E) Conjugated with glucuronide bu UDP glucuronosy ltransferase (UDPGT) to nontoxic, water-soluble conjugated bilirubin (Conj. Bili), and excreted in bile. Conjugated bilirubin is eliminated in stool; (F) but also broken down in the gut by bacteria to UCB which is reabsorbed back into the bloodstream, the so-called enterohepatic circulation. ${ }^{2}$

Jaundice in a newborn has been the all-time anxiety of the parents. This is because of the fear of toxicity of elevated bilirubin in the developing brain and immature organ systems. Unconjugated bilirubin (UCB), a natural antioxidant at the low level but is neurotoxic to the developing brain. Toxicity of bilirubin in otherwise healthy full-term infants and premature infants is highly debatable. ${ }^{3-6}$

The level of bilirubin that is regarded as safe in infants, particularly those who are preterm and have low birth weight is unknown. Bilirubin levels that are toxic to one infant may not be toxic to another, or even to the same infant in different clinical circumstances. Toxicity like acute bilirubin encephalopathy, chronic bilirubin encephalopathy (classical kernicterus), sensory neural deafness, intellectual deficit, etc., are irreversible if jaundice is not detected and treated early.

Therefore, various nonpharmacological and pharmacological treatment modalities have been tried for the treatment of neonatal jaundice. Though effective, relaible and relatively safe non pharmacological treatement modalities like widely used photothreapy and exchange tranfusion have been in use since long, but these have some limitations like long hospital stay, high cost, trained man power etc. in a resource poor setup. Therefore, search for alternate pharmocological threapy is going on for this condition. Fibrate group of drugs are such alternative pharmacological therapy for neonatal jaundice, being tried by various workers. Fibrate groups of drugs are hypolipidemic drugs. Fibrates act through activation of Peroxisome Proliferator-Activated Receptor (PPAR) alpha to modulate lipid oxidation and metabolism Fibrates also enhance bilirubin conjugation and excretion through induction of enzyme glucosyltransferase activity. Unconjugated bilirubin which is insoluble in water at neutral
$\mathrm{pH}$ after conjugation becomes non-toxic, water-soluble and excreted in bile.

Most of the studies of the effects of fibrates on hyperbilirubinemia have been done with clofibrate. ${ }^{7,8}$ Fenofibrate, a $2^{\text {nd }}$ generation fibrate has a similar mechanism of action as that of clofibrate but has lesser side effects and higher efficacy. In the adult population, fenofibrate has better safety than clofibrate and widely used as a hypolipidemic drug. ${ }^{9}$ Therefore, fenofibrate has replaced clofibrate as a drug for the treatment of hyperbilirubinemia. ${ }^{10}$ No serious side effects have been reported with a single dose administration of fenofibrate in the neonatal period. ${ }^{11}$

Though there are many studies with clofibrate, there is a paucity of studies on fenofibrate as a treatment modality of neonatal hyperbilirubinemia.

Considering this background, the present study was designed to assess the efficacy of oral fenofibrate and it's a possibility as adjuvant or alternative therapy in uncomplicated neonatal jaundice.

\section{MATERIALS AND METHODS}

This prospective study was conducted at Silchar Medical College and Hospital, Assam; a PG teaching hospital with a level III neonatal care unit. The study period was of one year duration, from July 2017 to June 2018. Prior Institutional Ethics Committee approval of the protocol was obtained and written informed consent was taken from one of the parents before the inclusion of the neonates to the study. Study design: Prospective, double-blinded randomized controlled trial. Randomization was done by closed envelope technique into two groups. The study population was newborn of age day 1 to day 7 admitted in NICU for jaundice. The babies were screened for exclusion criteria and were included after meeting the exclusion criteria. The exclusion criteria were - i. preterm infants $(<35$ weeks \& weight $<2 \mathrm{~kg}$ ), ii. conjugated bilirubin $>1.5 \mathrm{mg} / \mathrm{dl}$ or $15 \%$ of TSB iii. newborns with signs of sepsis, asphyxia, shock, congenital anomaly iv. metabolic disorders v. newborns on phototherapy before enrolment, referral vi. other reasons. Sample size: The sample size was 100 newborns divided into 2 groups- 50 in each group, A. Phototherapy (control group) B. Fenofibrate with phototherapy (intervention group).

Drug used: Since liquid preparation of fenofibrate was not available, a Tablet form of fenofibrate, was used. $145 \mathrm{mg}$ tablet of fenofibrate was dissolved in $14.5 \mathrm{ml}$ of distilled water so that $1 \mathrm{ml}$ of this solution is equivalent to $10 \mathrm{mg}$ of fenofibrate. The single oral dose of this solution was administered to the intervention group (group B) in the dose of $10 \mathrm{mg} / \mathrm{kg}$ and an equal amount of EBM was administered to the control group (phototherapy group, A). Both the groups were placed under phototherapy at a distance 
of $20 \mathrm{~cm}$ from the phototherapy lamps continuously with an interruption during breastfeeding only. Before starting the interventions, both the groups were evaluated for CBC, $\mathrm{ABO} \& \mathrm{Rh}$ group of both baby and mother, total bilirubin, reticulocyte count, PBS study, Coomb's test, G6PD. Total serum bilirubin measured every 12 hourly till TSB fell $2 \mathrm{mg} / \mathrm{dl}$ below the age-specific threshold according to AAP nomogram and phototherapy was stopped whenever that level was achieved. Before the discharge/stoppage of therapy serum urea, creatinine, LFT was done in the intervention group where drug toxicity suspected.

Baseline demographic variables such as gender, gestational age, birth weight, type of delivery were recorded. Data analysis: Comparative statistical analysis was carried out between the control and intervention groups. $p$ values were calculated using the student's t-test, chi-square test. $\mathrm{p}$ values $<0.05$ is considered as statistically significant. Statistical software used was SPSS, Graph Pad Quick Calcs and Microsoft Excel 2010.

\section{RESULTS}

Table 1 Baseline demographic variables n (\%)

\begin{tabular}{|l|c|c|c|c|}
\hline & $\begin{array}{c}\text { Control } \\
\text { group (A) }\end{array}$ & $\begin{array}{c}\text { Intervention } \\
\text { group (B) }\end{array}$ & p value & \\
\hline $\begin{array}{l}\text { Age in hrs } \\
\text { (mean) }\end{array}$ & 65.28 & 63.12 & 0.74 & Insignificant \\
\hline $\begin{array}{l}\text { Sex - } \\
\text { Male }\end{array}$ & $21(44)$ & $28(56)$ & 0.07 &,, \\
Female & $28(56)$ & $23(46)$ & & \\
\hline $\begin{array}{l}\text { Birth wt } \\
\text { (mean) }\end{array}$ & 2.6 & 2.7 & 0.714 &, \\
in kg & & & & \\
\hline
\end{tabular}

Table 2 Duration of phototherapy (in hours)

\begin{tabular}{|l|c|c|c|c|c|}
\hline & $\begin{array}{c}\text { Control } \\
\text { Group (A) }\end{array}$ & $\begin{array}{c}\text { Intervention } \\
\text { Group (B) }\end{array}$ & $\begin{array}{c}\text { T } \\
\text { score }\end{array}$ & $\begin{array}{c}\text { p } \\
\text { value }\end{array}$ & \\
\hline Mean & 21.12 & 16.56 & 2.27 & 0.024 & Significant \\
duration & \pm 12.9 & \pm 5.8 & & & \\
\hline
\end{tabular}

Table 3 Comparison of specific duration of phototherapy n $(\%)$

\begin{tabular}{|c|c|c|c|}
\hline $\begin{array}{c}\text { Duration of } \\
\text { photo- } \\
\text { therapy } \\
\text { (in hours) }\end{array}$ & $\begin{array}{c}\text { Control } \\
\text { group } \\
\text { (A) }\end{array}$ & $\begin{array}{c}\text { Intervention } \\
\text { group } \\
\text { (B) }\end{array}$ & $\begin{array}{c}\text { P } \\
\text { value }\end{array}$ \\
\hline$<12$ & $24(48)$ & $31(62)$ & \\
\hline $13-24$ & $20(40)$ & $19(38)$ & $\begin{array}{c}0.031, \\
\text { Significant }\end{array}$ \\
\hline $\begin{array}{c}>24 \\
(24-7 \text { days) }\end{array}$ & $6(12)$ & $0(0)$ & \\
\hline
\end{tabular}

Table 4 Mean TSB levels during treatment among control and intervention group (Bilirubin level in $\mathrm{mg} / \mathrm{dl}$ )

\begin{tabular}{|c|c|c|l|}
\hline $\begin{array}{c}\text { Time } \\
\text { in hrs }\end{array}$ & $\begin{array}{c}\text { Control } \\
\text { group (A) }\end{array}$ & $\begin{array}{c}\text { Intervention } \\
\text { group (B) }\end{array}$ & $\mathbf{p}$ value \\
\hline $\begin{array}{c}\text { On } \\
\text { admission }\end{array}$ & 16.6 & 16.8 & $\begin{array}{l}0.33, \\
\text { Insignificant }\end{array}$ \\
\hline 12 & 17.6 & 17.4 & 0.48 \\
\hline 24 & 16.2 & 15.1 & $\begin{array}{l}<0.005, \\
\text { Significant }\end{array}$ \\
\hline 48 & 14.8 & 13.3 & $<0.001$ \\
\hline
\end{tabular}

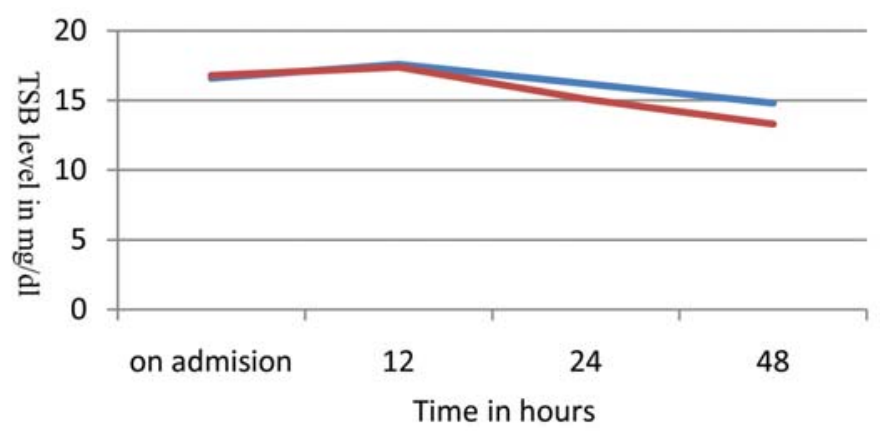

control group —intervention group

Figure 2 Line graph showing TSB levels during treatment among control and intervention group

\section{DISCUSSION}

Neonatal jaundice is a common problem faced by child health care providers and it is important for prompt treatment because of its effects on growth and development. Phototherapy and exchange blood transfusion have been in use as the main interventional therapy for neonatal jaundice. But as for drug therapy for this condition, very few drugs have been tried. Phenobarbitone is one of the drugs in use since long for the treatment of unconjugated hyperbilirubinemia. Another group of drugs, fibrates, though lipid-lowering drugs, also have similar actions like phenobarbitone like induction of the enzyme glucosyltransferase. Out of the fibrates, fenofibrate is easily available, inexpensive and relatively has a better safety profile.

The result of this study shows that the administration of fenofibrate with phototherapy i. reduces the duration of phototherapy and hospital stay (Table 2 and Table 3) ii. rapid reduction of bilirubin level (Table 4). Similar results were also found by El-Frargy et al. ${ }^{12}$ in their study in Egyptian neonates but they tried with 2 drugsphenobarbitone and fenofibrate in 2 separate groups. Significant reduction of TSB and duration of phototherapy were also reported by Ahmadpour KM et al from $\operatorname{Iran}^{13}$ and Bijay Kumar et al. ${ }^{14}$ from India. In another study by Gowda et al. ${ }^{15}$ in 100 neonates using a single oral dose of $5 \mathrm{mg} /$ $\mathrm{kg}$ of fenofibrate did not find any significant reduction in 
bilirubin levels at 12, 24 and 48 hours. This may be because of the low dose of fenofibrate.

No serious side effects of the drug were noted during the study period and follow up to 7 days except in one neonate in the fenofibrate group who developed diarrhea after 24 hours of phototherapy.

\section{CONCLUSION}

The present study shows that Fenofibrate is efficacious in the reduction of serum bilirubin as well as the duration of phototherapy in unconjugated neonatal hyperbilirubinemia. But this study is limited with the small number of sample sizes and short follow up. A large multicentric study with longer follows up is needed before recommending fenofibrate as a treatment modality of neonatal unconjugated hyperbilirubinemia or as an adjuvant to phototherapy.

Source of fund: None declared.

Conflict of interest: None declared.

Ethical clearance: Taken.

Author disclosure: (1) The article is original with the author(s) and does not infringe any copyright or violate any other right of any third party. (2) The article has not been published (whole or in part) elsewhere and is not being considered for publication elsewhere in any form, except as provided herein. (3) All author(s) have contributed sufficiently in the article to take public responsibility for it and (4) all author(s) have reviewed the final version of the above manuscript and approved it for publication.

\section{REFERENCES}

1. Hinkes $\mathrm{T}$ Michael, Cloherty $\mathrm{P}$ John. Neonatal hyperbilirubinemia. Manual of neonatal care; 4th ed. 1998;p.175.

2. Maisels, MJ, Newman TB. Kernicterus in otherwise healthy, breast-fed term new-borns. Pediatrics 1995;96(4 pt.1):730-3.

3. Newman TB, Maisels MJ. Does hyperbilirubinemia damage the brain of healthy full-term infant? Clin Perinatol 1990 Jun;17(2):331-58.

4. Newman TB, Maisels, MJ. Evaluation and treatment of jaundice in the term newborn: a kinder, gentler approach. Pediatrics 1992;89:809-818.
5. Watchko JF. Kernicterus in preterm newborns: past, present and future. Pediatrics 1992 Nov;90(5):707-15.

6. Shapiro SM. Bilirubin toxicity in the developing nervous system. Pediatr Neurol 2003;29:410-21.

7. Kutz K, Kandler H, Gugler R, Fevery J. Effect of clofibrate on metabolism of bilirubin, bromosulphophthalatein and indocyanine green and on the biliary lipid composition in Gilbert's Syndrome. Clin Sci 1984 Apr;66(4):389-97.

8. Habibi M, Mahyar A, Ayazi P, Ahmadababi F, Javadi A. The effect of clofibrate on hyperbilirubinemia of term neonate. Acta Med Iran 2012;50(1):21-5.

9. Mohammad Zadeh A, Farhat A Sh, Iranpour R. Effect of clofibrate in jaundiced term newborns. Indian Journal Pediatrics 2005;72(2):123-6.

10. Cuperus F, Hafkamp A, Hulzebos C, Verkade H. Pharmacological therapies for unconjugated hyperbilirubinemia. Curr Pharm Des 2009;15(25): 2927-38.

11. Chaudhary GS, Chaudhary V, Chaurasiya OS, Chandrakant V, Kumar V. Oral fenofibrate in neonatal hyperbilirubinemia: A randomized trial. Indian J Child Health 2016;3(1):54-8.

12. Gowda AN, Viswanathkumar HM, Yamuna BN, Daniel J. Efficacy of oral fenofibrate in the management of unconjugated hyperbilirubinemia in neonate. Int J Recent Trends in Sci and Tech 2014; 13(2):253-4.

13. Kumar B, Agarwal PK, Chorishi A, Dhaneria M. Fenofibrate: A novel approach in treating uncomplicated neonatal hyperbilirubinemia. People's J of Sci Res 2012;5(2):5-7.

14. Ahmadpour KM, Zahed PY, Moghaddamnia AA, Khafri S, Vafaeinezhad M. Effect of oral fenofibrate on serum bilirubin level in term neonate with hyperbilirubinemia. Intl J Pediatrics 2018;6(10):8317-26.

15. El-Frargy MS, El-Sharkawy HM, Attia GF. Therapeutic difference in some treatment modalities of jaundice in Egyptian neonates. $J$ of Clin Neonatology 2016;5(3):162. 